\title{
Obstruction of a Björk-Shiley mitral prosthesis in a patient with idiopathic hypertrophic subaortic stenosis
}

\author{
TAPAS RAYCHAUDHURY, A FAICHNEY, PR WALBAUM \\ From the Regional Cardiothoracic Centre, Royal Infirmary, Edinburgh
}

Mitral valve replacement by a low-profile disc prosthesis is an accepted form of treatment for a certain group of patients with idiopathic hypertrophic subaortic stenosis. ${ }^{12}$ Entrapment of chordal remnants between the disc and the valve ring, however, remains a potential hazard and such a risk is probably greater in patients with idiopathic hypertrophic subaortic stenosis who have an unusually small left ventricular cavity. ${ }^{3}$ We describe a patient in whom the disc of a Björk-Shiley mitral prosthesis was jammed by chordal tissues twice in succession during the period immediately after bypass, with a fatal outcome.

\section{Case report}

A 56-year-old man was referred for surgical abolition of his left ventricular outflow tract gradient. He had been complaining of central chest pain with radiation to the left arm for six years. Initially the onset of the pain was related to exertion, but for four years the pain had been present throughout the day, even when the patient was at rest. When first seen by the cardiologists he was having oral nitroglycerine and propranolol $40 \mathrm{mg}$ eight hourly. His electrocardiogram showed inferior ischaemia and right bundle-branch block and echocardiography showed septal hypertrophy. Cardiac catheterisation indicated normal left ventricular contraction, normal coronary arteries, and no resting gradient across the aortic valve. Isoprenaline provocation, however, at the rate of $0.35 \mu \mathrm{g} / \mathrm{kg} / \mathrm{min}$, produced a gradient of $130 \mathrm{~mm} \mathrm{Hg}$ across the aortic valve, with the simultaneous appearance of chest pain radiating to the left arm. His pain was not controlled by a daily dose of $360 \mathrm{mg}$ propranolol and he was therefore referred for surgery.

Mitral valve replacement was carried out under cardiopulmonary bypass with systemic cooling to $28^{\circ} \mathrm{C}$. At operation there were no detectable anatomical abnormalities and there was no palpable thrill over the aortic root. One litre of cold cardioplegic solution was delivered by root perfusion and cardioplegic arrest was rapid and satisfactory. There was no gross abnormality of the mitral valve, which was excised along with all the chordal tissues. The valve was replaced by a 33-mm Björk-Shiley mitral prosthesis. Before the left atrium was closed free

Address for reprint requests: Mr T Raychaudhury, Department of Cardiothoracic Surgery, Royal Infirmary, Edinburgh EH3 9YW.

Accepted 25 November 1982 movement of the valve disc was confirmed. The patient came off bypass without difficulty and maintained a satisfactory blood pressure. The effect of heparin was reversed with protamine and all cannulas were removed. At this stage there was a sudden drop in cardiac output with reduction of systemic blood pressure to zero. Electrical activity and left ventricular contraction continued without any appreciable cardiac output. No palpable or audible click from the prosthesis was apparent. Cardiopulmonary bypass was immediately re-established. The aorta was cross-clamped and $500 \mathrm{ml}$ of cardioplegic solution were infused. About four minutes elapsed between the loss of cardiac output and the re-establishment of cardiopulmonary bypass. During this period of arrest the nasopharyngeal temperature remained at $36.5^{\circ} \mathrm{C}$. When the left atrium was reopened the disc of the prosthesis was found to be jammed in the closed position and there were three chordal remnants trapped between the disc and the valve ring. The valve was forced open, all accessible chordal tissues were excised, including the apices of the papillary muscles, and the inflow ring of the prosthesis was rotated to ensure free and complete movement of the disc. Once again the patient came off bypass easily (cross-clamp time 40 minutes) and maintained a satisfactory output. As soon as the flow from the pump was reduced, there was another sudden drop in cardiac output. The flow was immediately increased and the aorta reclamped, after which $250 \mathrm{ml}$ of cardioplegic solution were infused. The left atrium was reopened and the prosthesis was found to be jammed once again in the closed position, this time by a pair of papillary muscles (figs 1 and 2). The prosthesis was excised and replaced by a 31-mm Carpentier Edwards bioprosthesis, though we had to accept that the protruding struts of the new prosthesis might produce some residual obstruction of the outflow tract. The patient came off the bypass easily (cross-clamp time 58 minutes) and maintained a satisfactory cardiac output. During the early postoperative period, however, it became apparent that he had sustained irreversible cerebral damage and he was pronounced dead on the fifth postoperative day. Throughout this time he maintained a satisfactory cardiac output and no murmur was audible on auscultation.

\section{Discussion}

Obstruction of a mechanical prosthesis owing to entrapment of thrombus, suture material, myocardium, and 388 


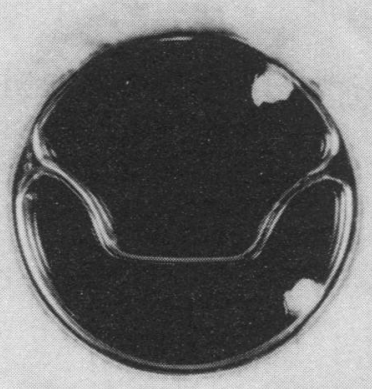

Fig 1 Björk-Shiley mitral prosthesis showing obstruction of the disc by a pair of papillary muscles.

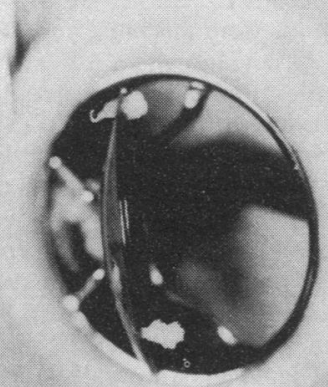

Fig 2 The mitral prosthesis after the disc was forced open.

chordal remnants has been reported by various authors. ${ }^{4-7}$ In all previous reports the excised native valve has been described as already diseased and there has been no report on patients with idiopathic hypertrophic subaortic stenosis, who despite morphologically normal leaflets may have considerable anatomical abnormalities of the subvalvular mechanism.

Patients with idiopathic hypertrophic subaortic stenosis have been reported as having not only a smaller left ventricular cavity but also abnormally located and oriented papillary muscles. Moreover, patients with longstanding obstruction may have secondary hypertrophy of the posterobasal wall, including the area immediately behind the posterior leaflet of the mitral valve just below the annulus. ${ }^{3}$ All these features can increase susceptibility to accidental entrapment of subvalvular tissues in a mechanical prosthesis, as happened in our patient.

In 1973 Henry et al described the abnormal systolic motion of the anterior mitral valve leaflet towards the interventricular septum in patients with idiopathic hypertrophic subaortic stenosis ${ }^{8}$ and in the same year Cooley et al published their successful results in a similar group of patients by performing mitral valve replacement. ${ }^{1}$ Subsequently, the value of mitral valve replacement in idiopathic hypertrophic subaortic stenosis has been challenged by Maron and his colleagues, who have also produced satisfactory results (as assessed by both the immediate and the late haemodynamic state of the patients) by performing transaortic left ventricular myotomy and myectomy. Nevertheless, there will remain some patients in whom mitral valve replacement will always be indicated, as pointed out by Bigelow and his colleagues. ${ }^{2}$ This group includes patients in whom $(a)$ the resting mitral regurgitation does not disappear even after abolition of the outflow tract gradient by angiotensin; $(b)$ the mitral valve cusps are grossly thickened; and (c) a serious atrioventricular conduction defect pre-exists. Moreover, a low-profile disc prosthesis, such as the Björk-Shiley or Cooley-Cutter, has been recommended as the prosthesis of choice to avoid any residual outflow tract obstruction. ${ }^{1}$

This case emphasises the need for complete excision of all chordal tissues and careful trimming of all papillary muscles whenever a tilting disc prosthesis is used to replace the mitral valve in patients with idiopathic hypertrophic subaortic stenosis.

\section{References}

' Cooley DA, Leachman RD, Wukasch DC. Diffuse muscular subaortic stenosis: surgical treatment. Am $J$ Cardiol 1973;31:1-6.

${ }^{2}$ Bigelow WG, Trimble AS, Douglas Wigle E, Adelman AG, Felderhof $\mathrm{CH}$. The treatment of muscular subaortic stenosis. $J$ Thorac Cardiovasc Surg 1974;63:384-92.

${ }^{3}$ Henry WL, Clark CE, Roberts WC, Morrow AG, Epstein SE. Differences in the distribution of myocardial abnormalities in patients with obstructive and non-obstructive asymmetric septal hypertrophy: echocardiographic and gross anatomic findings. Circulation 1974;50:447-55.

${ }^{4}$ Williams DB, Pluth JR, Orszulak TA. Extrinsic obstruction of the Björk-Shiley valve in the mitral position. Ann Thorac Surg 1981;32:58-62.

${ }^{5}$ Hammermerster KE, Dielurd DH, Kennedy JW. Severe intermittent mitral regurgitation in a Cross-Jones valve: report of a case with angiographic and haemodynamic observations. $J$ Thorac Cardiovasc Surg 1969;58:575-80.

${ }^{6}$ Kalke B, Korns ME, Goott B, Lillehei CW, Edwards JE. Engagement of ventricular myocardium by open-cage atrioventricular valvular prosthesis. J Thorac Cardiovasc Surg 1969;58:92-4.

'Shepard RL, Glancy DL, Stinson EB, Roberts WC. Haemodynamic confirmation of obstruction to left ventricular inflow by a caged ball prosthetic mitral valve.J Thorac Cardiovasc Surg 1973;65:252-4.

- Henry WL, Clark CE, Glancy DL, Epstein SE. Echocardiographic measurement of the left ventricular outflow gradient in idiopathic hypertrophic subaortic stenosis. $N$ Engl J Med 1973;288:989-93.

9 Maron BJ, Merrill WH, Freirer AP, Kent KM, Epstein SE, Morrow AG. Long-term clinical course and symptomatic status of patients after operation for hypertrophic subaortic stenosis. Circulation 1978;57:1205-13. 